\title{
A produção de livros digitais para o ensino presencial e remoto de Histologia ${ }^{\mathrm{I}}$
}

\section{Tatiana Montanari}

Departamento de Ciências Morfológicas, Instituto de Ciências Básicas da Saúde, Universidade Federal do Rio Grande do Sul, t.montanari@bol.com.br

\begin{abstract}
Resumo: Livros digitais foram desenvolvidos para apoiar o ensino de Histologia, disciplina das Ciências Morfológicas ministrada nos cursos de graduação de Ciências Biológicas e da Saúde. Sua concepção pedagógica referencia-se na descrição da inteligência naturalista, processamento cognitivo baseado no reconhecimento e na categorização de espécimes, habilidades importantes para a área morfológica. Os capítulos são ricamente ilustrados com imagens de células, tecidos e órgãos, obtidas em microscopia de luz e eletrônica, tendo em vista a importância da informação visual nesse campo do conhecimento. Exercícios criados com o programa Hot Potatoes procuram aumentar a interatividade e motivar a aprendizagem. Os recursos educacionais estão publicados na página institucional, com acesso livre: www.ufrgs.br/atlasbiocel, www.ufrgs.br/livrodehisto e www.ufrgs.br/auladehisto. Eles são utilizados como apoio didático-pedagógico nas aulas presenciais e no estudo extraclasse da disciplina Histologia (Ciências Biológicas). Na avaliação discente, a maioria considerou que eles contribuíram para a aprendizagem e que as imagens e os exercícios favoreceram a compreensão do conteúdo, como a identificação da estrutura celular e tecidual e a relação entre morfologia e atividade funcional, objetivos cognitivos definidos na estratégia pedagógica. Espera-se, com o seu desenvolvimento, contribuir para qualificar o ensino das Ciências Morfológicas.
\end{abstract}

Palavras-chave: Biologia celular; Histologia; Morfologia; livros digitais; educação a distância.

\section{The production of E-books for the Histology classroom teaching and E-learning}

Abstract: E-books were developed to help Histology teaching, a course of Morphological Sciences at the Biological and Health Sciences School. The pedagogical conception of the E-books were based on the description of the naturalist intelligence, cognitive processing on recognition and categorization of specimens, important concepts in the morphological sciences field. The chapters are richly illustrated with photographs of cells, tissues and organs, obtained from light and electron microscopy to provide visual information, another important aspect in this area of knowledge. There are tests created by Hot Potatoes software to enhance interactivity and to stimulate learning. The educational resources are available at the University homepage, with free access: www.ufrgs.br/atlasbiocel, www.ufrgs.br/livrodehisto and www.ufrgs.br/auladehisto. They are used as pedagogical support for Histology lectures and for extra class study (Biological Sciences). Majority of students reported that the Ebooks helped learning, and the images and exercises facilitated the understanding of the subject, for instance, the identification of the cell and tissue structure and the relationship between morphology and functional activity, cognitive aims defined in the

\footnotetext{
${ }^{\mathrm{I}}$ Menção honrosa para a apresentação em pôster dos resultados parciais no Congresso Brasileiro de Telemedicina e Telessaúde em 2017.
} 
educational strategy. I hope to contribute to improve Morphological Sciences teaching with the present virtual resources.

Keywords: Cell Biology; Histology; Morphology; E-book; E-learning.

Sessão do artigo: Educação a distância

\section{INTRODUÇÃO}

A disciplina Histologia contempla o estudo da célula, a unidade estrutural e funcional básica dos seres vivos; dos tecidos, agregados de células que funcionam de maneira coletiva, e dos órgãos, constituídos por um grupo de tecidos que realiza funções específicas. Ela pertence à área das Ciências Morfológicas e é ministrada no início dos cursos das Ciências Biológicas e da Saúde, sendo o seu conteúdo básico para a compreensão de informações de aplicação clínica, como aquelas abordadas nas disciplinas de Fisiologia e Patologia. Os principais objetivos da disciplina são: a identificação da estrutura celular e tecidual e a correlação dessa estrutura com a atividade funcional (Lowe \& Anderson, 2015, p. 1-4; Ross \& Pawlina, 2016, p. 1, 23, $73,98,105)$.

Muito do conhecimento nesse campo foi construído através da observação de células isoladas ou em cortes de tecidos ou órgãos ao microscópio de luz e ao microscópio eletrônico (de transmissão ou de varredura) (Alberts et al., 2015, p. 529, 554, 558; Ross \& Pawlina, 2016, p. 1-2). Assim, a informação visual é relevante no ensino dessa disciplina. Os livros-texto apresentam fotografias coloridas e podem ser acompanhados por CD-ROM ou código de acesso a ambientes virtuais com imagens, vídeos e animações (Geneser, 2003; Stith, 2004; Mcclean et al., 2005; Ovalle \& Nahirney, 2008; Lowe \& Anderson, 2015; Ross \& Pawlina, 2016). Geralmente metade da carga horária letiva é dedicada a atividades práticas, onde os alunos observam preparados permanentes ao microscópio de luz, e, nas aulas teóricas, são projetadas fotomicrografias (imagens obtidas ao microscópio de luz) e eletromicrografias (obtidas ao microscópio eletrônico) durante a exposição do conteúdo.

Há um incremento no uso da microscopia virtual, e ela já é uma realidade na maioria das universidades. Ela integra a microscopia de luz convencional com as tecnologias digitais. Preparados histológicos de excelência qualidade técnica e didática são fotografados em um microscópio fotográfico ou escaneados com um scanner de lâmina automático de alta resolução, e as imagens digitalizadas são armazenadas em arquivos ou servidores para observação na tela do computador ou em dispositivos móveis, como tablets e smartphones (Heidger et al., 2002; Santa-Rosa \& Struchiner, 2010; Santa-Rosa \& Struchiner, 2011; Viana et al., 2014; Ross \& Pawlina, 2016, p. 1, 20-21).

A adesão a laboratórios virtuais e atlas digitais mostra-se uma alternativa à dificuldade financeira das instituições para a montagem de salas de microscopia e para a manutenção dos equipamentos (Santa-Rosa \& Struchiner, 2010; Santa-Rosa \& Struchiner, 2011) e à deficiência operacional para a reposição das lâminas histológicas (Viana et al., 2014), por falta de profissional técnico capacitado e/ou pela qualidade inferior dos produtos adquiridos em modelos de compra como "pregão eletrônico", onde o preço da mercadoria é priorizado, sem ponderar custo-benefício, nesse caso, a durabilidade do produto gerado. 
A microscopia virtual otimiza o tempo do aluno e do professor no processo de aprendizagem e complementa o ensino presencial, pressionado pela sistemática redução da carga horária das disciplinas da área morfológica nas reformas curriculares dos cursos de Ciências Biológicas e da Saúde, pela expansão das vagas no ensino superior público, sem o devido incremento no corpo docente e pela inexperiência em microscopia do universitário ingressante. Ele geralmente não está familiarizado com o microscópio de luz, por causa da diminuição das atividades de experimentação em uma abordagem superficial de Ciências e de Biologia no ensino fundamental e médio (Heidger et al., 2002; Santa-Rosa \& Struchiner, 2010; Santa-Rosa \& Struchiner, 2011; Mancebo et al., 2015). Assim, em total contrassenso, um número menor de professores atende um número maior de alunos em uma quantidade menor de horas-aula quando mais tempo ambos necessitariam para o processo de ensino-aprendizagem de microscopia.

A atual geração (geração Z), conectada com a internet desde cedo, domina o ambiente virtual: utiliza hardware e periféricos destinados à comunicação e ao armazenamento de informações e comunica-se através das redes sociais e das ferramentas de compartilhamento de informação. Portanto, as estratégias metodológicas do ensino devem incluir as tecnologias de informação e comunicação (TIC) para fomentar a construção ativa do conhecimento (Santa-Rosa \& Struchiner, 2010; SantaRosa \& Struchiner, 2011; Bardini et al., 2016).

Nessa perspectiva e procurando contribuir para a autonomia no processo de aprendizagem das Ciências Morfológicas, foram desenvolvidos três livros digitais sobre Histologia.

\section{METODOLOGIA}

A concepção pedagógica dos livros digitais foi baseada na teoria das inteligências múltiplas de Howard Gardner. O neuropsicólogo norte-americano propõe que os seres humanos possuem uma série de capacidades cognitivas relativamente autônomas, designando-as inteligências, desenvolvidas para resolver problemas ou criar produtos. Cada inteligência representa uma forma distinta de representação mental. A inteligência naturalista é um tipo de processamento de informação baseado no reconhecimento e na categorização de espécimes e envolve a habilidade de fazer discriminações sequenciais e de detectar padrões (Gardner, 2001; Gardner, 2005; Gardner, 2007).

$\mathrm{Na}$ área das Ciências Morfológicas, às quais pertence a disciplina de Histologia, a informação visual é muito importante, e as habilidades de reconhecimento, classificação e categorização são fundamentais para a sua compreensão. Planejou-se possibilitar ao estudante o exercício de reconhecimento, comparação e classificação das células, dos tecidos ou dos órgãos, conforme suas características estruturais e ainda relacionar seu aspecto morfológico com a sua atividade funcional. Para tanto, as imagens foram priorizadas no design dos recursos educacionais, e, na navegação, seu acesso foi facilitado através da organização em categorias típicas da área. Foram selecionadas fotografias obtidas em microscopia de luz e em microscopia eletrônica das células e dos seus constituintes, dos tecidos e dos órgãos. Elas foram provenientes do acervo de aulas práticas e de projetos de pesquisa.

Os livros foram publicados na página da universidade, com acesso livre e depositados em repositórios da instituição. Para o registro da autoria, uma cópia impressa de cada livro foi encaminhada ao Escritório de Direitos Autorais da Fundação 
Biblioteca Nacional, RJ. Como editora pessoa física, o ISBN (international standard book number) de cada obra foi solicitado à Agência Brasileira do ISBN da mesma fundação (ISBN, 2012).

O contador Clustrmaps ou WidgetContador é utilizado para acompanhar o número de acessos e a sua distribuição geográfica.

\section{RESULTADOS E DISCUSSÃO}

Procurando contribuir com a produção de materiais educacionais que promovam a autonomia do aluno no processo de aprendizagem de Histologia, foram desenvolvidos três livros digitais: Atlas digital de Biologia celular e tecidual, auladehisto e Histologia: texto, atlas e roteiro de aulas práticas. A proposta de elaboração de vários recursos virtuais para o estudo dessa disciplina é alinhada com a opinião do neuropsicólogo Howard Gardner, principal autor de suporte cognitivo-pedagógico do trabalho. Ele defende a importância de se ofertar múltiplos recursos aos alunos, em vários formatos e linguagens representando o mesmo conteúdo (Gardner, 2005). A relevância da informação visual e a importância das habilidades de reconhecimento, classificação e categorização na área morfológica priorizaram as imagens no seu design. Estudos mostram a importância da linguagem visual na aprendizagem (Mayer \& Gallini, 1990; McClean et al., 2005).

\section{Atlas digital de Biologia celular e tecidual}

Inicialmente a navegação foi construída com o programa Macromedia Flash; a coleção de imagens foi organizada em três grandes tópicos: Célula, Tecidos e Sistemas, sendo subdivididos nos seus constituintes; o acesso às imagens (acompanhadas de legendas) dava-se por tópicos ou subtópicos do menu, presente na tela inicial e nas demais telas do sistema; a informação sobre a localização do visitante estava sempre disponível; as legendas eram sucintas, com a descrição do material biológico, a técnica utilizada e o aumento (Figura 1). Com o auxílio do software Hot Potatoes, foram criados exercícios de preencher lacunas, palavras-cruzadas, escolha múltipla (quiz) e de associação, inclusive com diagnóstico de imagens; a seção com os exercícios foi agregada ao atlas através do programa Adobe Dreamweaver (Barilli et al., 2007; Montanari et al., 2007a; Montanari et al., 2007b; Montanari et al., 2008).

$\mathrm{O}$ atlas foi publicado na página da universidade, com acesso livre e cadastrado no repositório CESTA. Para verificar sua aplicabilidade, foi avaliado pelos alunos da disciplina de Biologia Celular (curso de Biologia marinha) no primeiro semestre letivo de 2008, segundo os itens: relevância para os objetivos e as necessidades cognitivas da disciplina, facilidade de orientação na navegação, recursos para valorizar as imagens (sinalização e clareza das legendas), contribuição dos exercícios para a aprendizagem e aplicação do conteúdo. A avaliação discente da primeira versão do atlas ( 25 alunos de 34 matriculados) sugeriu o aumento na sinalização das estruturas e a inclusão de textos sobre as células e os tecidos mencionados e revelou a necessidade de diminuir o tempo para baixar as imagens (Montanari, 2014). 


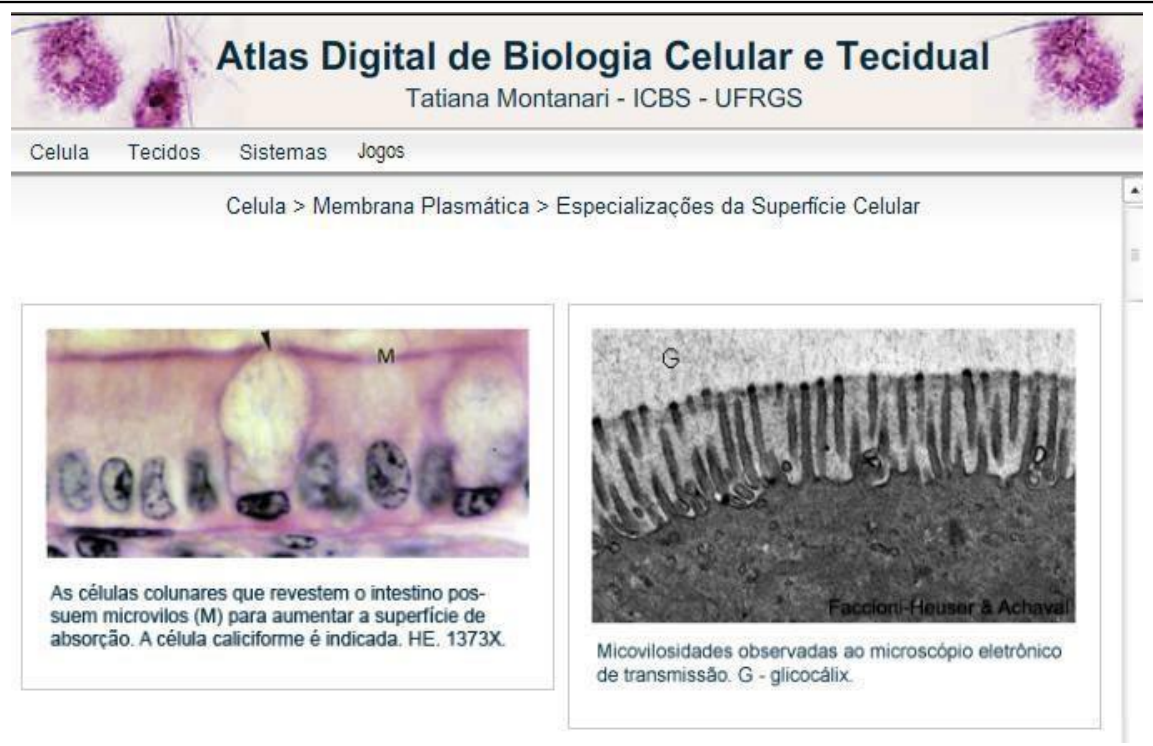

Figura 1 - Tela do tópico Célula na primeira versão do atlas digital: imagens obtidas em microscopia de luz ou eletrônica são acompanhadas de legendas sucintas.

Essas críticas foram consideradas para a elaboração de uma nova versão, usando o programa Adobe Dreamweaver para construir a navegação e apresentando o conteúdo em capítulos redigidos no Word e salvos em PDF; a sinalização das estruturas foi ampliada, e as imagens foram acompanhadas de legendas e texto explicativo (Figura 2). O atlas foi disponibilizado em: www.ufrgs.br/atlasbiocel e, além do repositório CESTA, foi depositado no LUME (Montanari, 2016a). Foi citado nas referências bibliográficas do plano de ensino da disciplina Histologia (curso de Ciências Biológicas) e avaliado pelos alunos segundo os critérios anteriormente expostos ao final do primeiro semestre letivo de 2016 (Montanari, 2016b), de 2017 (Montanari, 2018) e de 2018.

A avaliação discente da segunda versão, com 23 alunos de 58 matriculados no primeiro semestre de 2016 (Montanari, 2016b), 11 alunos de 44 matriculados no primeiro semestre de 2017 (Montanari, 2018) e 33 alunos de 49 matriculados no primeiro semestre de 2018, assim como a anterior, mostrou que o atlas digital contribuiu para alcançar os objetivos da disciplina, possibilitando a identificação de detalhes na morfologia das células e a compreensão da relação entre a forma e a função das células. A navegação no Adobe Dreamweaver e a publicação de arquivos em PDF deram rapidez para baixar as telas. Por outro lado, a atual versão, com acréscimo de texto explicativo e apresentação do conteúdo em páginas sequencias, diminuiu a motivação para o estudo quando comparada com a anterior criada com o Macromedia Flash (Tabela 1). A participação menor na enquete sobre este livro, resultante da não consulta, remete às considerações de Gardner sobre a resistência ao aprendizado: "As pessoas relutam em alterar as práticas com quais foram criadas e com as quais já estão confortáveis demais" (Gardner, 2007, p. 136). Esses alunos, ao estudar para as provas, consultaram os livros da área e/ou revisaram as anotações das aulas teóricas ou práticas. 


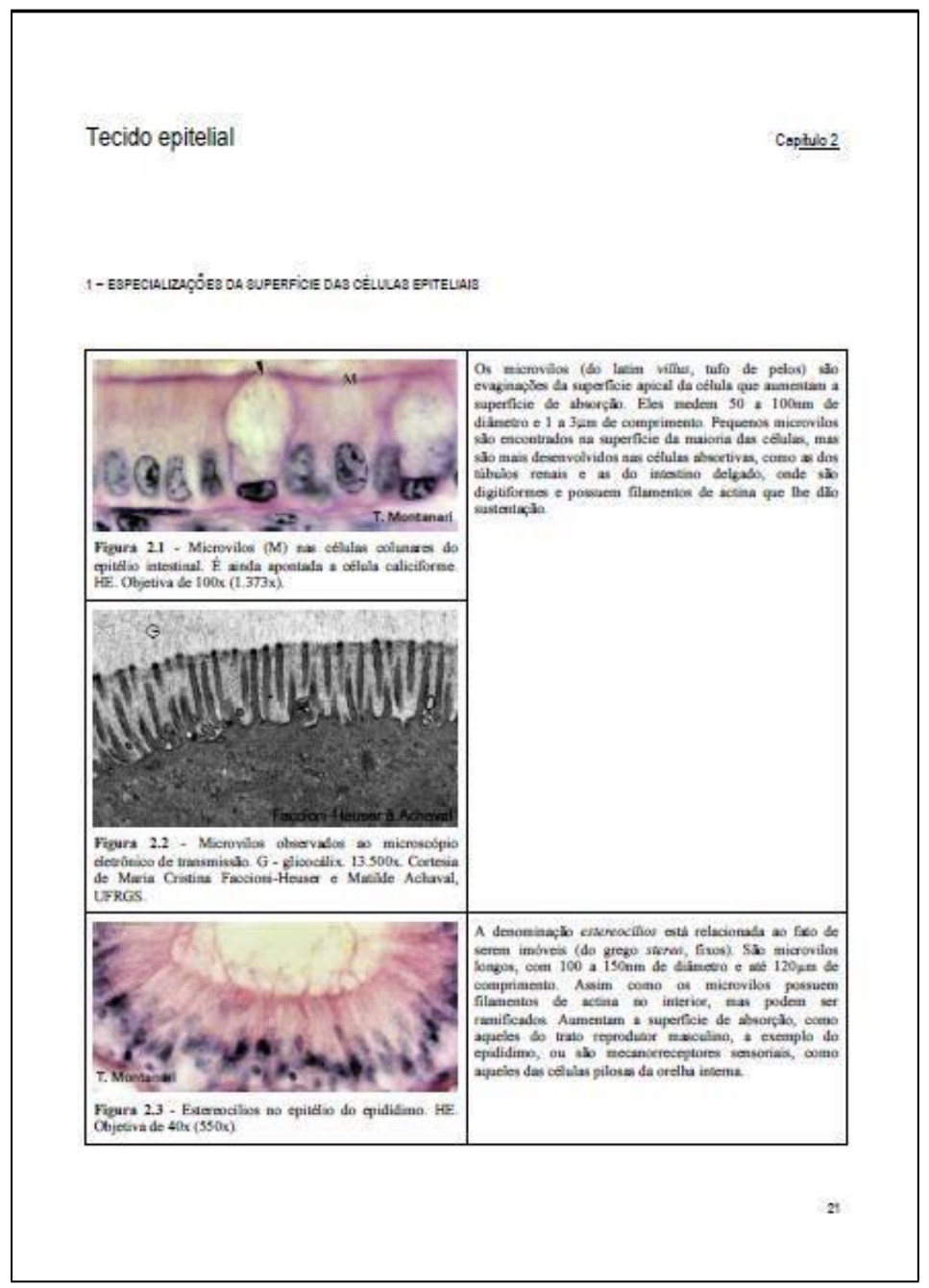

Figura 2 - Página do capítulo de Tecido Epitelial da versão final do atlas digital: fotomicrografias e eletromicrografias acompanhadas de legendas e texto explicativo.

\section{auladehisto}

A navegação foi desenvolvida com o Adobe Dreamweaver; o conteúdo, como abordado em sala de aula, é apresentado em telas do PowerPoint, com os arquivos salvos em PDF, para tornar a leitura mais dinâmica (Figura 3). Nesse recurso educacional, foram incluídos os exercícios elaborados com o programa Hot Potatoes para aumentar a interatividade e motivar a aprendizagem (Figura 4). O auladehisto está publicado em: www.ufrgs.br/auladehisto e depositado no LUME (Montanari, 2016c). Foi utilizado nas aulas presenciais da disciplina Histologia (curso de Ciências Biológicas) e indicado nas referências do plano de ensino para o estudo remoto, sendo avaliado pelos alunos segundo os itens já mencionados ao final do primeiro semestre de 2016 (Montanari, 2016b), de 2017 (Montanari, 2017; Montanari, 2018) e de 2018. 


\section{PROJEÇÕES CELULARES}

Microvilos
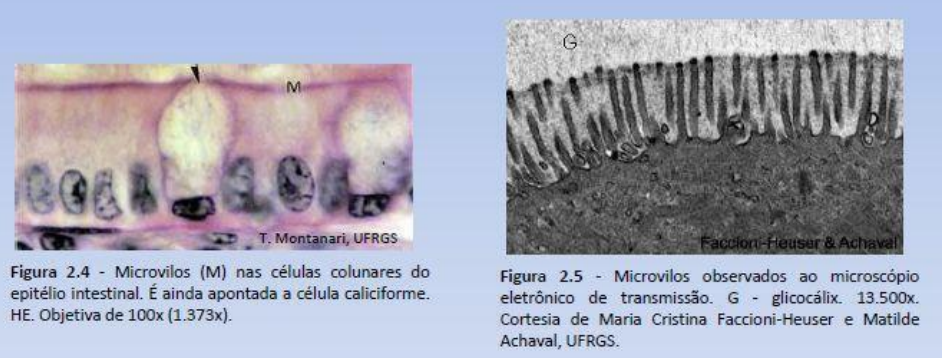

Os microvilos são evaginaçōes digitiformes da superfície apical, com 50 a $100 \mathrm{~nm}$ de diâmetro e 1 a 3 um de comprimento. Filamentos de actina dão-lhe sustentação. Essas projeções aumentam a superficie de absorção, ocorrendo em células absortivas, como as do intestino e as do túbulo renal.

Figura 3 - Tela do tópico Tecido Epitelial do auladehisto, exibindo fotografias comparativas da mesma estrutura ao microscópio de luz e ao microscópio eletrônico.
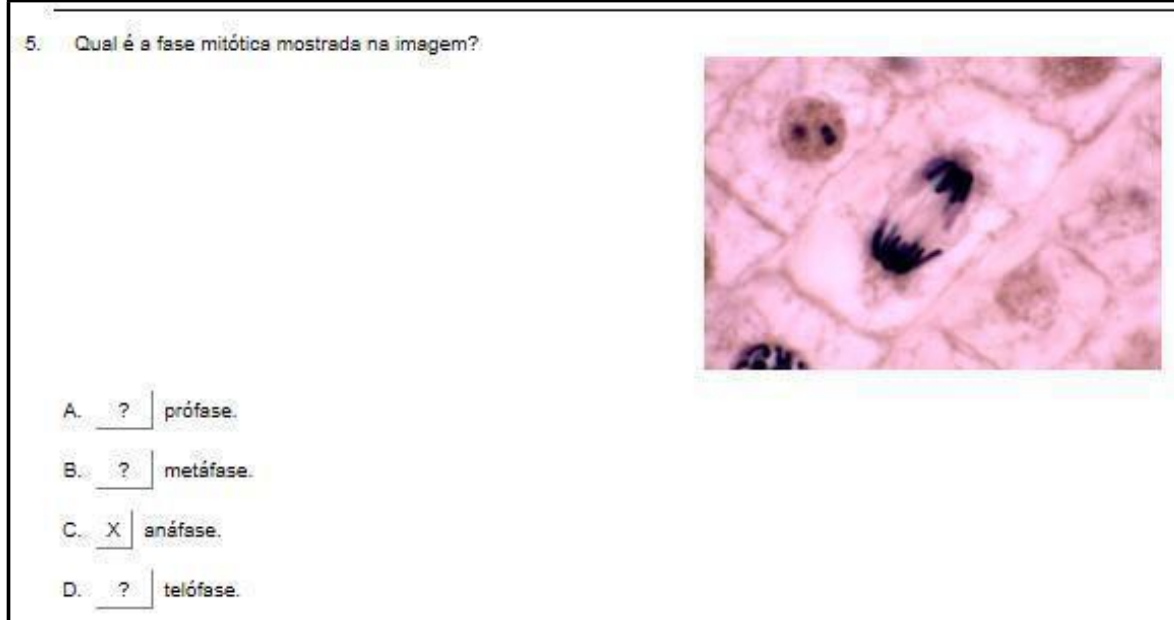

Figura 4 - Exercício de escolha múltipla com diagnóstico de imagem.

Segundo a avaliação discente, com 33 alunos de 58 matriculados no primeiro semestre de 2016 (Montanari, 2016b), 17 alunos de 44 matriculados no primeiro semestre de 2017 (Montanari, 2017; Montanari, 2018) e 36 alunos de 49 matriculados no primeiro semestre de 2018, o auladehisto contribuiu para alcançar os objetivos da disciplina, como a identificação da morfologia celular e a compreensão da sua relação com a função. Ele foi considerado mais estimulante para o estudo e foi mais acessado do que o atlas digital (Tabela 1). 
Tabela 1 - Resultados da avaliação discente do Atlas digital de Biologia celular $e$ tecidual* e do auladehisto**. $^{* *}$.

\begin{tabular}{|c|c|c|c|c|c|c|}
\hline \multirow[b]{2}{*}{ Critério avaliado } & \multicolumn{3}{|c|}{ atlasbiocel } & \multicolumn{3}{|c|}{ auladehisto } \\
\hline & Sim & Parcial & Não & Sim & Parcial & Não \\
\hline $\begin{array}{l}\text { Contribuiu para alcançar os objetivos da } \\
\text { disciplina? }\end{array}$ & $72 \%$ & $25 \%$ & $2 \%^{\mathrm{a}}$ & $74 \%$ & $26 \%$ & \\
\hline Motivou o estudo do conteúdo? & $40 \%$ & $51 \%$ & $9 \%$ & $56 \%$ & $38 \%$ & $5 \%^{\mathrm{a}}$ \\
\hline $\begin{array}{l}\text { As imagens contribuíram para a identificação } \\
\text { de detalhes na morfologia das células? }\end{array}$ & $81 \%$ & $18 \%^{\mathrm{a}}$ & & $78 \%$ & $21 \%$ & $1 \%$ \\
\hline $\begin{array}{l}\text { Contribuiu para a compreensão da relação entre } \\
\text { forma e função? }\end{array}$ & $64 \%$ & $33 \%$ & $3 \%$ & $77 \%$ & $20 \%$ & $2 \%^{\mathrm{a}}$ \\
\hline \multicolumn{7}{|l|}{ Facilidade de orientação na navegação: } \\
\hline $\begin{array}{l}\text { As informações foram facilmente encontradas } \\
\text { para estudo e pesquisa do conteúdo? }\end{array}$ & $84 \%$ & $13 \%$ & $3 \%$ & $82 \%$ & $15 \%$ & $2 \%^{\mathrm{a}}$ \\
\hline $\begin{array}{l}\text { O menu permitiu a navegação pelo conjunto de } \\
\text { telas com facilidade? }\end{array}$ & $85 \%$ & $15 \%$ & & $83 \%$ & $14 \%$ & $2 \%^{\mathrm{a}}$ \\
\hline $\begin{array}{l}\text { Teve alguma dificuldade para acessar o } \\
\text { conteúdo? }\end{array}$ & $4 \%$ & $5 \%$ & $91 \%$ & $3 \%$ & $4 \%$ & $93 \%$ \\
\hline Por ex., demora para baixar as telas? & $1 \%$ & $3 \%$ & $96 \%$ & $2 \%$ & $5 \%$ & $93 \%$ \\
\hline \multicolumn{7}{|l|}{ Recursos para valorizar as imagens: } \\
\hline As imagens são nítidas? & $69 \%$ & $30 \%^{a}$ & & $65 \%$ & $32 \%$ & $1 \%{ }^{\mathrm{b}}$ \\
\hline $\begin{array}{l}\text { Os tecidos, as células e os seus constituinte } \\
\text { foram adequadamente identificados através d } \\
\text { setas? }\end{array}$ & $60 \%$ & $39 \%$ & $1 \%$ & $51 \%$ & $46 \%$ & $2 \%^{\mathrm{a}}$ \\
\hline $\begin{array}{l}\text { As legendas e o texto foram bem } \\
\text { compreendidos? }\end{array}$ & $66 \%$ & $28 \%$ & $5 \%{ }^{\mathrm{a}}$ & $67 \%$ & $30 \%$ & $2 \%^{\mathrm{a}}$ \\
\hline O tamanho da letra foi adequado? & $93 \%$ & $6 \%{ }^{\mathrm{a}}$ & & $85 \%$ & $12 \%$ & $2 \%^{\mathrm{a}}$ \\
\hline \multicolumn{7}{|l|}{ Sobre a aplicação do conteúdo: } \\
\hline $\begin{array}{l}\text { Você acredita que domina o conteúdo para } \\
\text { fazer uma avaliação tranquila? }\end{array}$ & $27 \%$ & $54 \%$ & $18 \%^{\mathrm{a}}$ & $22 \%$ & $55 \%$ & $21 \%^{\mathrm{b}}$ \\
\hline $\begin{array}{l}\text { Aplicou (ou acredita que aplicará) o conteúdo a } \\
\text { outras disciplinas? }\end{array}$ & $60 \%$ & $30 \%$ & $10 \%$ & $57 \%$ & $38 \%$ & $4 \%{ }^{\mathrm{a}}$ \\
\hline $\begin{array}{l}\text { Utilizará as habilidades de estudo em ambient } \\
\text { virtual em outras áreas do curso ou da vid } \\
\text { profissional? }\end{array}$ & $67 \%$ & $29 \%$ & $3 \%^{\mathrm{a}}$ & $70 \%$ & $24 \%$ & $4 \%^{\mathrm{b}}$ \\
\hline
\end{tabular}

Disciplina Histologia (curso de Ciências Biológicas), 2016-2018: * 67 alunos; ** 86 alunos; não responderam: $\mathrm{a}-1 \%, \mathrm{~b}-2 \%$.

\section{Histologia: texto, atlas e roteiro de aulas práticas}

Esse livro foi redigido a partir dos roteiros de aula da disciplina Histologia Humana (curso de Enfermagem), ministrada no Departamento de Ciências Morfológicas ao longo de vários anos. Em dado momento, os alunos solicitaram que os slides fossem 
colocados na apostila, e a inclusão das imagens foi viabilizada pelo recebimento de um fotomicroscópio Olympus do Programa de Modernização da Infraestrutura das Instituições Federais de Ensino Superior e Hospitais Universitários do Ministério da Educação em 2002. Nesse equipamento, para o estudo extraclasse, sob a orientação docente, um grupo de quatro alunas fotografou parte da coleção de lâminas da disciplina. Muitas dessas fotomicrografias foram selecionadas para o livro. $\mathrm{O}$ registro fotográfico foi continuado pela autora. As lâminas histológicas fotografadas foram confeccionadas nos Laboratórios de Histologia e Ultramicrotomia do Departamento. A primeira edição do livro foi publicada pela editora da universidade no lançamento da série Graduação (Montanari, 2006).

Visando fomentar a sua acessibilidade, a segunda edição foi disponibilizada na internet. A navegação foi construída em HTML, com o programa Adobe Dreamweaver. Os capítulos redigidos no Word foram apresentados como arquivos em PDF. Um capítulo introdutório sobre Célula foi acrescentado, e eletromicrografias foram incluídas nesse e em outros capítulos. Elas eram provenientes do Mestrado em Biologia celular na Universidade Estadual de Campinas (UNICAMP), sob orientação da Prof ${ }^{\mathrm{a}}$ Dra Heidi Dolder, e dos projetos de pesquisa de colegas do Departamento e de suas orientadas (Montanari, 2013).

Para a terceira edição do livro digital, o texto foi revisado e atualizado; quadros comparativos foram elaborados para facilitar a compreensão, e as fontes bibliográficas foram apresentadas como notas de rodapé. Imagens foram adicionadas: estas são procedentes da digitalização dos diapositivos de lâminas histológicas do curso de Medicina da UNICAMP, fotografadas durante o Mestrado; do material realizado no período de docência na atual instituição (diapositivos e ilustrações para retroprojeção), e de fotomicrografias e eletromicrografias das pesquisas de colegas do Departamento. Essa edição substituiu a anterior no endereço: www.ufrgs.br/livrodehisto e foi registrada no repositório LUME (Montanari, 2016d).

Do caos se fez a luz: Na revisão e atualização para a terceira edição do livro Histologia: texto, atlas e roteiro de aulas práticas, foram consultadas as referências da área: livros clássicos, como Ham \& Cormack (1983) e Weiss \& Greep (1984); livros-texto comumente usados na graduação, como Gartner \& Hiatt (2007), Ovalle \& Nahirney (2008) e Junqueira \& Carneiro (2013); livros mais robustos, com informações mais detalhadas, como Alberts et al. (2002), Geneser (2003) e Ross \& Pawlina (2012), e livros com enfoque na clínica (Snell, 1985; Lowe \& Anderson, 2015). A ordem dos capítulos da segunda edição foi seguida para a leitura dos capítulos desses livros, sendo preparado um capítulo por vez. Foram realizadas anotações manuscritas na cópia impressa da edição anterior, em diferentes cores e marcações, citando o autor e a(s) página(s). Posteriormente foram digitadas essas informações, com nova redação dos parágrafos. As referências foram mencionadas como notas de rodapé. O texto impresso ou na tela do computador foi lido; as informações foram confirmadas nas fontes bibliográficas, parágrafo por parágrafo, e referências foram excluídas ou adicionadas. Modificações na redação também foram efetuadas, visando facilitar a compreensão. Imagens foram acrescentadas.

Dividir o todo em partes: Capítulos longos, como Tecido conjuntivo e Sistema digestório, tratados em mais de um capítulo nos livros-texto, foram segmentados no momento da construção: por exemplo, o Sistema digestório foi dividido em: Cavidade oral, Tubo digestório e Anexos, e cada uma dessas seções foi subdividida: Cavidade oral - língua e glândulas salivares; Tubo digestório - esôfago, estômago, intestino delgado e intestino grosso, e Anexos - pâncreas, fígado e vesícula biliar. Isso foi 
necessário para facilitar a leitura e a compreensão do conteúdo nos livros-texto e a posterior redação no livro da autora.

Para a próxima edição: Determinadas informações não foram abordadas, mas foram assinaladas nos livros de referência para serem tratadas em uma próxima edição. Assim, evitou-se entrar em alguns temas mais áridos, como determinados aspectos moleculares, que, embora tratados pelos livros-texto de Histologia, não são apropriados para disciplinas de graduação.

O resultado: O livro Histologia: texto, atlas e roteiro de aulas práticas apresenta um texto conciso que agrega os avanços no conhecimento da Biologia celular à Histologia descritiva tradicional. A primeira edição exibia fotomicrografias dos tecidos e órgãos (Montanari, 2006). A segunda edição, com a inclusão de um capítulo sobre Célula, acrescentou eletromicrografias das células e dos seus constituintes (Montanari, 2013). $\mathrm{Na}$ terceira edição, imagens foram adicionadas com a digitalização dos diapositivos e das transparências para retroprojeção preparados durante a pós-graduação e a docência. Quadros comparativos foram elaborados para facilitar a compreensão, e quadros coloridos destacam do texto informações sobre histórico, coloração, histologia comparada e aplicação clínica, procurando despertar o interesse do aluno sobre esses temas (Montanari, 2016d). Desde a primeira edição, há questionário para revisão do conteúdo ao final do capítulo e, de forma inédita entre os livros de Histologia, roteiros para as aulas práticas com sugestão de lâminas para representação. Esses roteiros, inicialmente inseridos em cada capítulo, foram agrupados em um capítulo sobre Prática nas edições publicadas na internet para facilitar a sua impressão. Essa localização também favorece a impressão do texto do livro quando não se pretende imprimir os roteiros de práticas.

Como as referências eram mencionadas ao final de cada capítulo, ao começar a revisão do conteúdo para a terceira edição, sentiu-se a necessidade de precisar as fontes no texto. A decisão de citá-las como notas de rodapé foi inspirada na coleção $O s$ Pensadores (Durant, 1996), já que esse tipo de citação é comum nos livros de Ciências Sociais e Humanas, mas não naqueles de Morfologia. Era algo importante a se fazer, tendo em vista a divergência de informações entre os autores e até mesmo entre edições do mesmo autor, mas, por causa disso e da própria dificuldade na sua realização, mostrou-se uma árdua tarefa. Na redação da próxima edição, facilitará a atualização.

Uma amostra da editoração do livrodehisto é exibida no printscreen da página do capítulo de Tecido Epitelial (Figura 5). Esse livro não foi submetido à avaliação discente, pois, ao terminar essa edição, já se pensava na próxima com a separação de informações e imagens para tal. 


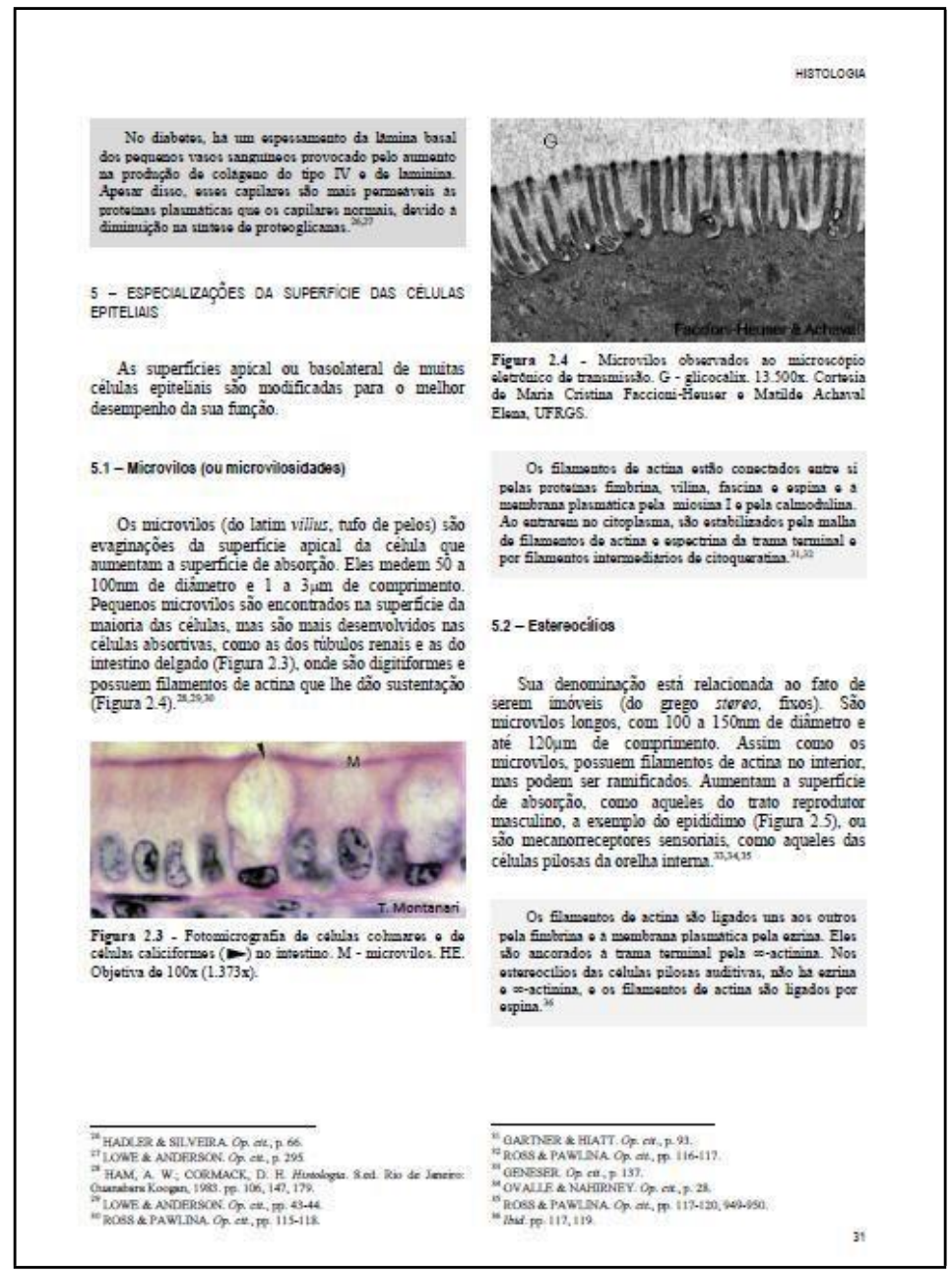

Figura 5 - Página do capítulo de Tecido Epitelial do livro de Histologia, que exemplifica a sua estrutura: o conteúdo é abordado com imagens obtidas em microscopia de luz e eletrônica e legendas descritivas sobre o material biológico; informações sobre relações clínicas e aspectos moleculares são apresentadas em quadros destacados, e as referências são citadas como notas de rodapé.

\section{CONSIDERAÇÕES FINAIS}

A microscopia virtual é uma ferramenta importante para o ensino presencial e remoto de Histologia. Ela consiste na digitalização dos preparados histológicos para observação na tela do computador ou em dispositivos móveis. A adesão a essa tecnologia pelas instituições é impulsionada pelas dificuldades na manutenção dos laboratórios de prática e na confecção dos preparados histológicos. Além disso, ela otimiza o tempo do aluno e do professor no processo de aprendizagem e complementa o ensino presencial, pressionado pela redução da carga horária nas reformas curriculares, pela expansão das vagas no ensino superior e pela inexperiência em microscopia do universitário ingressante. A atual geração é adepta às TIC para o estudo remoto e colaborativo, e as práticas pedagógicas devem fomentar a construção ativa do conhecimento com essas estratégias metodológicas.

Procurando contribuir com a produção de materiais educacionais que promovam a autonomia do aluno no processo de aprendizagem de Histologia, foram desenvolvidos três livros digitais: Atlas digital de Biologia celular e tecidual, auladehisto e Histologia: 
texto, atlas e roteiro de aulas práticas. Houve uma preocupação em apresentar informação qualificada e atualizada para o estudante subsidiar a construção do conhecimento nas disciplinas sequenciais, com enfoque clínico e para se capacitar para o mercado de trabalho na docência ou na pesquisa na área morfológica ou em áreas afins. Uma coleção de imagens provenientes de material de ensino e de pesquisa foi ofertada para facilitar a compreensão do conteúdo. Recursos de interatividade, como os exercícios elaborados com o programa Hot Potatoes, foram disponibilizados para estimular o processo pedagógico. $\mathrm{O}$ acesso livre pela internet confere independência espacial e temporal no estudo do conteúdo. As avaliações da aplicabilidade do atlas digital e do auladehisto indicaram que o objetivo cognitivo de promover a compreensão da identificação da estrutura celular e tecidual e da relação entre morfologia e atividade funcional foi alcançado. O contador de acessos mostra a receptividade desses recursos educacionais. Espera-se, com o desenvolvimento desses livros digitais, contribuir para qualificar o ensino das Ciências Morfológicas.

\section{AGRADECIMENTOS}

A Eliane de Oliveira Borges (Departamento de Fisiologia, ICBS, UFRGS) pela orientação com o programa Hot Potatoes, pelas ilustrações realizadas no Adobe Illustrator e pelo desenvolvimento da navegação dos livros digitais. A Diorlon Nunes Machado (monitor do programa de monitoria a distância para disciplina presencial, PROGRAD/SEAD, UFRGS - 2016 e 2017) e a Alexandre Morales (técnico de Tecnologia da Informação do ICBS, UFRGS) pela ajuda com a navegação do auladehisto. A Gabriela Perry pelo desenvolvimento do design e da navegação da primeira versão do atlas digital. A Raymundo Carlos Machado Ferreira pela navegação dos exercícios.

A Griscelda da Conceição da Silva, Thaís de Oliveira Plá, Daiene Tórgo Fabretti e Marta Silvana da Motta pelo registro fotográfico de parte da coleção de lâminas da disciplina Histologia humana. A Sofia Louise Santin Barilli pela digitalização da maioria das fotomicrografias. A Leonardo Lisbôa da Motta pela digitalização de parte das eletromicrografias e pela publicação das imagens e das legendas na primeira versão do atlas digital.

Às Prof ${ }^{\text {as }}$ Maria Cristina Faccioni Heuser, Matilde Achaval Elena, Tais Malysz, Patrícia Nascimento e Fabiana Rigon por várias das eletromicrografias que ilustram os livros digitais, e à Prof ${ }^{\mathrm{a}}$ Simone Marcuzzo e aos seus orientados Francele Valente Piazza e André Luís Ferreira de Meireles pelas fotomicrografias de tecido nervoso.

À Secretaria de Educação a Distância (SEAD) da UFRGS pelo apoio através de bolsa aos acadêmicos Leonardo Lisbôa da Motta em 2007 e Diorlon Nunes Machado em 2016 e 2017.

Agradecimento póstumo à Dra Maria Isabel Timm (Centro Nacional de Supercomputação - CESUP, UFRGS) pela coordenação do projeto do atlas digital na sua primeira versão.

\section{REFERÊNCIAS}

ALBERTS, B.; JOHNSON, A.; LEWIS, J.; MORGAN, D.; RAFF, M.; ROBERTS, K.; WALTER, P. Molecular Biology of the Cell. 6.ed. New York: Garland Science, 2015. p. 529, $554,558$.

ALBERTS, B.; JOHNSON, A.; LEWIS, J.; RAFF, M.; ROBERTS, K.; WALTER, P.

Molecular Biology of the cell. 4.ed. New York: Garland Science, 2002. 1463 p. 
BARDINI, V. S. dos S.; SPALDING, M.; VASCONCELOS, L.; SILVEIRA, V.; SALGADO, M. A. Práticas pedagógicas no ensino de histologia: estratégias para incentivar o aluno na consolidação dos conhecimentos. Revista Brasileira de Ensino Superior, v. 2, n. 4, p. 15-21, out.-dez. 2016. Disponível em:

$<$ https://seer.imed.edu.br/index.php/REBES/article/view/1380/1070>. Acesso em: 13 maio 2017.

BARILLI, S. L. S.; TIMM, M. I.; PERRY, G. T.; MÔTTA, L. L. de; MONTANARI, T. Atlas digital de biologia celular e tecidual. In: FEIRA DE INICIAÇÃO CIENTÍFICA, 16., 2007, Porto Alegre. Livro de Resumos. Porto Alegre: UFRGS, 2007. p. 979-980. Disponível em:

<http://www.lume.ufrgs.br/handle/10183/33601>. Acesso em: 13 set. 2017.

DURANT, W. A história da Filosofia. In: CIVITA, V. (Ed.). Os Pensadores. Rio de Janeiro: Nova Cultural, 1996. 480 p.

GARDNER, H. Inteligência: um conceito reformulado. Rio de Janeiro: Objetiva, 2001. 347 p. GARDNER, H. Mentes que mudam: a arte e a ciência de mudar as nossas idéias e a dos outros. Porto Alegre: Artmed/Bookman, 2005. 229 p.

GARDNER, H. Cinco mentes para o futuro. Porto Alegre: Artmed, 2007. 160 p.

GARTNER, L. P.; HIATT, J. L. Tratado de Histologia em cores. 3.ed. Rio de Janeiro: Elsevier, 2007. 426 p.

GENESER, F. Histologia: com bases moleculares. 3.ed. Buenos Aires: Médica Panamericana/ Rio de Janeiro: Guanabara Koogan, 2003. 616 p.

HAM, A. W.; CORMACK, D. H. Histologia. 8.ed. Rio de Janeiro: Guanabara Koogan, 1983. $907 \mathrm{p}$.

HEIDGER Jr., P. M.; DEE, F.; CONSOER, D.; LEAVEN, T.; DUCAN, J.; KREITER, C. Integrated approach to teaching and testing in Histology with real and virtual imaging. The Anatomical Record, v. 269, p. 107-112, 2002. Disponível em:

<http://onlinelibrary.wiley.com/doi/10.1002/ar.10078/epdf>. Acesso em: 4 maio 2017.

ISBN. Manual do editor. 8. ed. Rio de Janeiro: Fundação Biblioteca Nacional, 2012. p. 11.

JUNQUEIRA, L. C.; CARNEIRO, J. Histologia básica: texto e atlas. 12.ed. Rio de Janeiro: Guanabara Koogan, 2013. 538 p.

LOWE, J. S.; ANDERSON, P. G. Stevens \& Lowe's Human Histology. 4.ed. Philadelphia: Elsevier, Mosby, 2015. 429 p.

MANCEBO, D.; VALE, A. A.; MARTINS, T. B. Políticas de expansão da educação superior no Brasil 1995-2010. Revista Brasileira de Educação, v. 20, n. 60, p. 31-50, 2015. Disponível em: <http://www.scielo.br/pdf/rbedu/v20n60/1413-2478-rbedu-20-60-0031.pdf〉. Acesso em: 13 maio 2017.

MAYER, R. E.; GALLINI, J. K. When is an illustration worth ten thousand words? Journal of Educational Psychology, v. 82, n. 4, p. 715-726, 1990.

MCCLEAN, P.; JOHNSON, C.; ROGERS, R.; DANIELS, L.; REBER, J.; SLATOR, B. M.; TERPSTRA, J.; WHITE, A. Molecular and cellular Biology animations: development and impact on student learning. Cell Biology Education, v. 4, p. 169-179, 2005. Disponível em:

<https://www.ncbi.nlm.nih.gov/pmc/articles/PMC1103718/pdf/i1536-7509-4-2-169.pdf>.

Acesso em: 4 maio 2017.

MONTANARI, T. Histologia: texto, atlas e roteiro de aulas práticas. Porto Alegre: Ed. da UFRGS, 2006. 155 p.

MONTANARI, T. Histologia: texto, atlas e roteiro de aulas práticas. 2.ed. Porto Alegre: Ed. da autora, 2013. 203 p. Disponível em:

$<$ https://professor.ufrgs.br/tatianamontanari/files/livrodehisto2.ed_.pdf >;

$<$ http://www.bibliotecadigital.ufrgs.br/da.php?nrb=000899951\&loc=2015\&l=655f5e24140b95e

2>. Acesso em: 13 maio 2017.

MONTANARI, T. Construção e aplicação de objeto de aprendizagem para o ensino de Biologia celular e tecidual. In: CONGRESSO BRASILEIRO DE ENSINO SUPERIOR A 
DISTÂNCIA (ESUD), 11., 2014, Florianópolis. Anais. Florianópolis: UNIREDE. 2014. p. 422-431. Disponível em: <http://esud2014.nute.ufsc.br/anais-esud2014/files/pdf/125789.pdf>. Acesso em: 13 set. 2017.

MONTANARI, T. Atlas digital de biologia celular e tecidual. Porto Alegre: Ed. da autora, 2016a. Disponível em: <https://www.ufrgs.br/atlasbiocel>;

$<$ http://cesta2.cinted.ufrgs.br/xmlui/handle/123456789/388>;

<http://www.lume.ufrgs.br/handle/10183/157069> Acesso em: 13 set. 2017.

MONTANARI, T. Recursos virtuais para o ensino presencial e remoto de Histologia. RENOTE

- Revista Novas Tecnologias na Educação, v. 14, n. 2, p. 1-12, 2016b. Disponível em: <http://seer.ufrgs.br/index.php/renote/article/view/70635>. Acesso em: 13 set. 2017.

MONTANARI, T. auladehisto Porto Alegre: Ed. da autora, 2016c. Disponível em: <https://www.ufrgs.br/auladehisto>; <http://www.lume.ufrgs.br/handle/10183/164696>. Acesso em: 13 set. 2017.

MONTANARI, T. Histologia: texto, atlas e roteiro de aulas práticas. 3.ed. Porto Alegre: Ed. da autora, 2016d. Disponível em: <https://www.ufrgs.br/livrodehisto>;

<http://www.lume.ufrgs.br/handle/10183/147986>. Acesso em: 13 set. 2017.

MONTANARI, T. Ambiente virtual para o ensino de Histologia. In: SEMANA CIENTÍFICA DO HCPA, 37., 2017, Porto Alegre. Anais. Clinical \& Biomedical Research, Porto Alegre: HCPA, v. 37 (supl.), p. 104, 2017. Disponível em:

<https://www.hcpa.edu.br/downloads/pesquisa/RevistaCientifica/2017/anais_semana_cient_hcp a_2017.pdf>. Acesso em: 12 dez. 2018.

MONTANARI, T. A produção de livros digitais para o ensino de Histologia. In: CONGRESSO BRASILEIRO DE TELEMEDICINA E TELE-SAÚDE, 8., 2017, Gramado: Associação Brasileira de Telemedicina e Telessaúde. Anais. Jornal Brasileiro de Telessaúde, Rio de Janeiro: UERJ, v. 5, n. 1, p. 157, 2018. Disponível em:

<http://www.telessaude.uerj.br/jornal/volume/download_artigo/776>. Acesso em: 12 dez. 2018.

MONTANARI, T.; TIMM, M. I.; PERRY, G. T.; MÔTTA, L. L. de; BARILLI, S. L. S. Atlas digital de biologia celular. In: SALÃO DE GRADUAÇÃO, 2. e SALÃO DE EDUCAÇÃO A DISTÂNCIA, 3., 2007, Porto Alegre. Anais. Porto Alegre: UFRGS, 2007a. p. 1-5. Disponível em: <http://www.ufrgs.br/salao_ead_grad/salao2007/anais/projetos.html>. Acesso em: 13 set. 2017.

MONTANARI, T.; TIMM, M. I.; PERRY, G. T.; MÔTTA, L. L. de; BARILlI, S. L. S. Recurso digital para apoio ao aprendizado de Biologia celular e tecidual. RENOTE - Revista Novas Tecnologias na Educação, v. 5, p. 1-11, 2007b. Disponível em:

<http://seer.ufrgs.br/index.php/renote/article/view/14179>. Acesso em: 13 set. 2017.

MONTANARI, T.; TIMM, M. I.; BARILLI, S. L. S. ; PERRY, G. T.; MÔTTA, L. L. de. Atlas digital de biologia celular e tecidual: imagens em microscopia de luz e eletrônica e jogos. In: SALÃO DE GRADUAÇÃO, 3. e SALÃO DE EDUCAÇÃ̃O A DISTÂNCIA, 4., 2008, Porto Alegre. Anais. Porto Alegre: UFRGS, 2008. p. 1-5. Disponível em:

<http://www.lume.ufrgs.br/handle/10183/93661>. Acesso em: 13 set. 2017.

OVALLE, W. K.; NAHIRNEY, P. C. Netter Bases da Histologia. Rio de Janeiro: Elsevier, 2008. $493 \mathrm{p}$.

ROSS, M. H.; PAWLINA, W. Histologia: texto e atlas, em correlação com Biologia celular e molecular. 6.ed. Rio de Janeiro: Guanabara Koogan, 2012. 987 p.

ROSS, M. H.; PAWLINA, W. Histologia: texto e atlas, correlações com Biologia celular e molecular. 7.ed. Rio de Janeiro: Guanabara Koogan, 2016. p. 1-2, 23, 73, 98, 105.

SANTA-ROSA, J. G.; STRUCHINER, M. Design participativo de um ambiente virtual de aprendizagem de Histologia. Revista Brasileira de Pesquisa em Educação em Ciências, v. 10, n. 2, 2010. Disponível em:

<https://seer.ufmg.br/index.php/rbpec/article/view/2177/1577>. Acesso em: 4 maio 2017.

SANTA-ROSA, J. G.; STRUCHINER, M. Tecnologia educacional no contexto do ensino de Histologia: pesquisa e desenvolvimento de um ambiente virtual de ensino e aprendizagem. 
Revista Brasileira de Educação Médica, v. 35, n. 2, p. 289-298, 2011. Disponível em: <http://www.scielo.br/pdf/rbem/v35n2/20.pdf〉. Acesso em: 4 maio 2017.

SNELL, R. S. Histologia clínica. Rio de Janeiro: Discos CBS, Interamericana, 1985. 686 p. STITH, B. J. Use of animation in teaching Cell biology. Cell Biology Education, v. 3, p. 181188, 2004. Disponível em:

<https://www.ncbi.nlm.nih.gov/pmc/articles/PMC520841/pdf/i1536-7509-3-3-181.pdf〉. Acesso em: 4 maio 2017.

VIANA, G. M.; BACCHI, R. R.; OLIVEIRA, T. V. C.; ANTUNES, D. T. Atlas digital no auxílio e aprendizado de histologia e de citologia. In: FÓRUM ENSINO, PESQUISA, EXTENSÃO E GESTÃo (FEPEG), 8., 2014, Montes Claros. Resumos. Montes Claros: UNIMONTES (Universidade Estadual de Montes Claros), 2014. Disponível em:

<http://www.fepeg2014.unimontes.br/sites/default/files/resumos/arquivo_pdf_anais/atlas_digita 1_no_auxilio_e_aprendizado_de_histologia_e_de_citologia.pdf $>$. Acesso em: 13 maio 2017.

WEISS, L.; GREEP, R. O. Histologia. 4.ed. Rio de Janeiro: Guanabara Koogan, 1981. 1016 p. 